Gareth L. Ackland John R. Prowle

\section{Presepsin: solving a soluble (CD14) problem in sepsis?}

Received: 14 December 2014

Accepted: 30 December 2014

Published online: 22 January 2015

(C) Springer-Verlag Berlin Heidelberg and ESICM 2015

G. L. Ackland (『)

Clinical Physiology, Medicine, University College London, London, UK

e-mail: g.ackland@ucl.ac.uk

\section{J. R. Prowle}

Adult Critical Care Unit, The Royal London Hospital,

Barts Health NHS Trust, London, UK

Presepsin—soluble CD14 (sCD14)—has attracted significant attention from several clinical research groups recently as a prognostic biomarker in sepsis. In a recent issue of Intensive Care Medicine, Masson and colleagues analyzed a subset of data from the ALBIOS trial to explore the potential of sCD14 as a biomarker in sepsis [1]. In this ALBIOS sub-study, these authors examined the prognostic significance of $\mathrm{sCD} 14$ measured at enrollment and on days 2 and 7 in 997 critically ill patients with sepsis, adding to a burgeoning body of published studies examining the relationship between sCD14 and the presence [2] or severity [3, 4] of sepsis.

Notable contributions made by this sub-study relate to three main findings. First, higher baseline sCD14 level was associated with both the severity and number of organs demonstrating dysfunction-both initially and over time. In multivariable analysis, higher sCD14 levels were most strongly correlated with renal and liver dysfunction. $\mathrm{sCD} 14$ is a $13-\mathrm{kDa}$ peptide and hence likely to be cleared in the kidney. Thus, the close association between higher sCD14 levels and kidney dysfunction can partly be explained by impaired sCD14 clearance, as suggested by highly elevated sCD14 levels in patients with advanced acute kidney injury and end-stage renal disease [5].

Second, the ALBIOS sub-study found that baseline sCD14 level was higher when there was subsequent microbiological evidence of bacterial infection, in particular with Gram-negative organisms and abdominal or urinary tract sources of infection. This observation lends biological plausibility to $\mathrm{sCD} 14$ as a prognostic biomarker in sepsis but also suggests that its clinical utility might be restricted to infections with significant endotoxin exposure. In potentially the most impactful finding of the ALBIOS sub-study, sCD14 levels tended to decrease over time in intensive care unit (ICU) survivors, but tended to increase in patients with positive microbiology and inappropriate antibiotic therapy. This suggests a potential for testing biomarker-directed antibiotic escalation and de-escalation strategies. However, as inappropriate antibiotic therapy predominantly occurred in patients with multiply resistant Gram-negative infections, it is difficult to judge the potential of sCD14 to discriminate treatment failure in resistant Gram-positive or fungal infections.

Third, higher baseline sCD14 levels were associated with ICU death (in septic shock) and death before 90 days (in severe sepsis and septic shock). When added to a clinical risk-prediction model, sCD14 significantly improved risk-classification as assessed by category-free net classification index (cfNRI). However, this finding should be interpreted with some caution, as cfNRI reflects only the direction and not the magnitude of risk reclassification [6].

A fundamental tenet of adopting a clinical biomarker is establishing a robust basic mechanistic link to a clinical phenotype [7]. Considerable uncertainty is attached to the precise biologic role of sCD14 (Fig. 1). Membrane CD14 is a co-receptor for endotoxin through toll-like receptor 


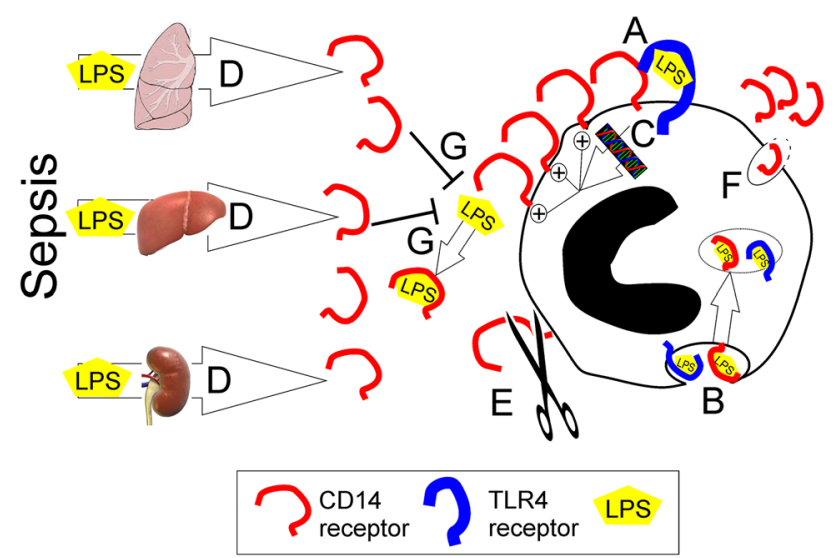

Fig. 1 Mechanisms through which sCD14 fuels, or attenuates, inflammation. A Membrane CD14 (presepsin) is a co-receptor for endotoxin through toll-like receptor (TLR) 2 and TLR-4 transmembrane signaling, $B$ CD14 is also a co-receptor within the endosomal compartment, $D$ endotoxin upregulates transcription of CD14 mRNA in monocytes, $D$ endotoxin also induces transcription of CD14 in epithelial cells from several organs, including lung, kidney, and liver, $E, F \mathrm{sCD} 14$ is produced either through proteolytic cleavage on activated monocytes $(E)$ or by secretion of a larger $56-\mathrm{kDa}$ form $(F), G$ sCD14 receptors compete with membrane-bound sCD14 for free ligand. LPS Lipopolysaccharide

(TLR) 2 and TLR-4 trans-membrane signalling, both at the cell surface and within the endosomal compartment [8]. Endotoxin has long been suspected as being a pathogenic driver for multi-organ dysfunction. Furthermore, endotoxin is linked mechanistically to the pathogenesis of several chronic syndromes/diseases with a higher propensity for acquiring sepsis (such as cardiac failure) [9]. Chronic activation of the immune system as a consequence of circulating, gut-derived microbial products fuels a myriad of inflammatory diseases, including human immunodeficiency virus-related systemic immune activation [10]. Consistent with these findings, sCD14 predicts higher incident cardiovascular risk [11]. However, CD14 is not just primarily expressed on monocytes/ macrophages; cell membrane or secreted CD14 protein also occurs in cells of non-hematopoietic origin [12].
Endotoxin induces transcription of CD14 mRNA in epithelial cells from several organs, including lung, kidney, and liver, as well as endothelial, microglial and vascular smooth muscle cells [12]. sCD14 is produced either through proteolytic cleavage on activated monocytes or by the secretion of a larger $56-\mathrm{kDa}$ form [13, 14]. Importantly, sCD14 receptors can compete with the membrane-bound forms for free ligand, thereby preventing cytokine release and facilitating lipopolysaccharide transfer to lipoproteins [13]. Thus, sCD14 may play an anti-inflammatory role, in part by boosting immunocompetence through increasing immunoglobulin production by B cells [15]. CD14 also plays an important metabolic regulatory role relevant to critical illness, in a TLR4independent manner. Genetic ablation of CD14 decreases body fat, preserves bone mineral content, and extends lifespan in experimental models of high-fat, obesityinduced insulin resistance that cause cardiovascular pathophysiology [16]. Thus, the direct mechanistic link(s) between sCD14 and organ dysfunction remain very unclear. Endogenous molecules, drugs, and therapeutic interventions differentially downregulate CD14, thus potentially masking the true prognostic significance of circulating presepsin. For example, glucocorticoids downregulate CD14 expression in monocytes [17], and propofol reduces CD14 expression in whole blood, yet preserves HLA-DR [18], a competing prognostic biomarker [19]. These observations highlight the importance of understanding the mechanisms underlying the variable expression of molecules touted as biomarkers with future clinical utility [20].

Thus, presepsin joins a long line of biomarkers that have either already failed, or continue to strive, to refine critical care therapies and interventions. Clearly, prospective evaluation studies are required to establish precisely how mechanistically robust aspects of presepsin biology may be exploited clinically. The ALBIOS substudy is one of several early reports hinting that the solubility of CD14 may yet contribute in helping resolve such an apparently insoluble problem as predicting outcomes, and guiding therapy, in sepsis.

\section{References}

1. Masson S, Caironi P, Fanizza C, Thomae R, Bernasconi R, Noto A, Oggioni R, Pasetti GS, Romero M, Tognoni G, Latini R, Gattinoni L (2015) Circulating presepsin (soluble CD14 subtype) as a marker of host response in patients with severe sepsis or septic shock: data from the multicenter, randomized ALBIOS trial. Intensive Care Med 41:12-20. doi:10.1007/s00134-014-3514-2
2. Kweon OJ, Choi JH, Park SK, Park AJ (2014) Usefulness of presepsin (sCD14 subtype) measurements as a new marker for the diagnosis and prediction of disease severity of sepsis in the Korean population. J Crit Care 29:965-970
3. Behnes M, Bertsch T, Lepiorz D, Lang S, Trinkmann F, Brueckmann M, Borggrefe M, Hoffmann U (2014) Diagnostic and prognostic utility of soluble CD 14 subtype (presepsin) for severe sepsis and septic shock during the first week of intensive care treatment. Crit Care 18:507 
4. Liu B, Yin Q, Chen YX, Zhao YZ, Li CS (2014) Role of presepsin (sCD14$\mathrm{ST}$ ) and the CURB65 scoring system in predicting severity and outcome of community-acquired pneumonia in an emergency department. Respir Med 108:1204-1213

5. Nakamura $Y$, Ishikura $H$, Nishida $T$, Kawano Y, Yuge R, Ichiki R, Murai A (2014) Usefulness of presepsin in the diagnosis of sepsis in patients with or without acute kidney injury. BMC Anesthesiol 14:88

6. Kerr KF, Wang Z, Janes H, McClelland RL, Psaty BM, Pepe MS (2014) Net reclassification indices for evaluating risk prediction instruments: a critical review. Epidemiology 25:114-121

7. Puntmann VO (2009) How-to guide on biomarkers: biomarker definitions, validation and applications with examples from cardiovascular disease. Postgrad Med J 85:538-545

8. Ulevitch RJ, Tobias PS (1995)

Receptor-dependent mechanisms of cell stimulation by bacterial endotoxin. Annu Rev Immunol 13:437-457

9. Rauchhaus M, Doehner W, Francis DP, Davos C, Kemp M, Liebenthal C, Niebauer J, Hooper J, Volk HD, Coats AJ, Anker SD (2000) Plasma cytokine parameters and mortality in patients with chronic heart failure. Circulation 102:3060-3067

10. Brenchley JM, Price DA, Schacker TW, Asher TE, Silvestri G, Rao S, Kazzaz Z, Bornstein E, Lambotte O, Altmann D, Blazar BR, Rodriguez B, TeixeiraJohnson L, Landay A, Martin JN, Hecht FM, Picker LJ, Lederman MM, Deeks SG, Douek DC (2006) Microbial translocation is a cause of systemic immune activation in chronic HIV infection. Nat Med 12:1365-1371
11. Reiner AP, Lange EM, Jenny NS, Chaves PH, Ellis J, Li J, Walston J, Lange LA, Cushman M, Tracy RP (2013) Soluble CD14: genomewide association analysis and relationship to cardiovascular risk and mortality in older adults. Arterioscler Thromb Vasc Biol 33:158-164

12. Jersmann HP (2005) Time to abandon dogma: CD14 is expressed by nonmyeloid lineage cells. Immunol Cell Biol 83:462-467

13. Haziot A, Rong GW, Bazil V, Silver J, Goyert SM (1994) Recombinant soluble CD14 inhibits LPS-induced tumor necrosis factor-alpha production by cells in whole blood. J Immunol 152:5868-5876

14. Labeta MO, Durieux JJ, Fernandez N, Herrmann R, Ferrara P (1993) Release from a human monocyte-like cell line of two different soluble forms of the lipopolysaccharide receptor, CD14. Eur J Immunol 23:2144-2151

15. Filipp D, Alizadeh-Khiavi K, Richardson C, Palma A, Paredes N, Takeuchi O, Akira S, Julius M (2001) Soluble CD14 enriched in colostrum and milk induces B cell growth and differentiation. Proc Natl Acad Sci USA 98:603-608

16. Zanoni I, Granucci F (2013) Role of CD14 in host protection against infections and in metabolism regulation. Front Cell Infect Microbiol $3: 32$
17. Scherberich JE, Nockher WA (1999) CD14++ monocytes, CD14+/CD16+ subset and soluble CD14 as biological markers of inflammatory systemic diseases and monitoring immunosuppressive therapy. Clin Chem Lab Med 37:209-213

18. Larsen B, Hoff G, Wilhelm W, Buchinger H, Wanner GA, Bauer M (1998) Effect of intravenous anesthetics on spontaneous and endotoxinstimulated cytokine response in cultured human whole blood. Anesthesiology 89:1218-1227

19. Landelle C, Lepape A, Voirin N, Tognet E, Venet F, Bohe J, Vanhems P, Monneret G (2010) Low monocyte human leukocyte antigen-DR is independently associated with nosocomial infections after septic shock. Intensive Care Med 36:1859-1866

20. Pachot A, Monneret G, Brion A, Venet F, Bohe J, Bienvenu J, Mougin B, Lepape A (2005) Messenger RNA expression of major histocompatibility complex class II genes in whole blood from septic shock patients. Critical care medicine 33:31-38 (discussion 236-237) 